\title{
Oxydation von Lecithin bei Gegenwart von Eisensalz.
}

\author{
Vorläufige Mitteilung.
}

Von

Otto Warburg und Otto Meyerhof.

(Aus der Zoologischen Station in Neapel.)

(Der Redaktion zugegangen am 13. Mai 1913.)

Im Laufe einer Untersuchung über die Oxydationsprozesse in Zellen stießen wir auf eine Tatsache, die uns für die chemische Seite des Problems von großer Tragweite zu sein scheint.

Bekanntlich sind die Substanzen, aus denen sich die Zelle aufbaut, und die in sauerstoffatmenden Zellen dauernd, direkt oder indirekt, oxydiert werden, außerhalb der Zelle bei den in Betracht kommenden Temperaturen von $20-40^{\circ}$ gegenüber Sauerstoff relativ beständig; sie oxydieren sich außerhalb der Zelle mit einer Geschwindigkeit, die außerordentlich klein ist im Vergleich zu ihrer Oxydationsgeschwindigkeit in der lebenden Zelle. Das gilt beispielsweise für die Nucleinsäuren, Histone, Eiweißkörper, Fette, Lecithine, Zuckerarten usw. Auch Mischungen dieser Körper zeigen die gleiche Indifferenz gegenüber Sauerstoff.

Wir haben nun gefunden, da $B$ das als "Lecithin" bezeichnete Substanzgemisch sich bei Zimmertemperatur mit großer Geschwindigkeit an der Luft oxydiert, wenn man seiner wässerigen. Suspension etwas Eisensalz zusetzt.

Höchstwahrscheinlich ist zum Zustandekommen der Reaktion die Anwesenheit einer kleinen Menge H-Ion erforderlich; die käuflichen Präparate von Merck und Kahlbaum, die wir benutzten, waren gegen Lackmuspapier schwach sauer und oxydierten sich, wenn Eisensalz zugesetzt wurde, während Zusatz von H-Ion ohne erheblichen Einfluß auf die Oxydationsgeschwindig- 
keit war. Ein von uns selbst aus Eiern dargestelltes Lecithinpräparat dagegen war gegen Lackmuspapier völlig neutral und hier mußte eine kleine Menge H-Ion zugesetzt werden, wenn erhebliche $0 x y$ dationsgeschwindigkeiten erhalten werden sollten.

Von etwa 50 Messungen, die alle im gleichen Sinne verliefen, wollen wir hier 3 mitteilen. Die Versuchstemperatur war. $22^{\circ}$; die Suspensionen wurden mit Luft geschüttelt und der Sauerstoffverbrauch aus der auftretenden Druckabnahme berechnet. Das Eisensalz wurde in Form von Eisenoxydulammonsulfat zugegeben.

1. $23 \mathrm{mg}$ "Lecithin ex ovo» Merck + $2 \mathrm{ccm}$ Wasser verbrauchten in $2^{1 / 2}$ Stunden keine meßbare Menge Sauerstoff.

2. $23 \mathrm{mg}$ "Lecithin ex ovo" Merck $+2 \mathrm{ccm}$ Wasser $+0,1 \mathrm{mg}$ Fe verbrauchten in 1 Stunde $0,12 \mathrm{~cm}\left(0^{\circ}, 760 \mathrm{~mm}\right)$ Sauerstoff.

$3.23 \mathrm{mg}$ "Lecithin ex ovo" Merck $+2 \mathrm{ccm} \mathrm{H}_{2} \mathrm{O}$ $+0,1 \mathrm{mg}$ Fe verbrauchten in $2^{1} / 2$ Stunden $0,18 \mathrm{~cm}\left(0^{0}, 760 \mathrm{~mm}\right)$ Sauerstoff.

4. $40 \mathrm{mg}$ Lecithin (neutrales Präparat, aus Hühnereiern dargestellt) $+2 \mathrm{ccm} n / 1000$-Essigsäure $+0,1 \mathrm{mg}$ Fe verbrauchten in 1 Stunde $0,19 \mathrm{ccm}\left(0^{\circ}, 760 \mathrm{~mm}\right)$ Sauerstoff.

Bei passend gewählten Mengenverhältnissen (viel Lecithin, wenig Edsen) bleibt die Oxydationsgeschwindig:keit lange Zeit, z. B. 9 Stunden lang, fast konstant.

Wie steht es nun mit der Größenordnung der von uns in vitro beobachteten Oxydationsgeschwindigkeit im Vergleich zu der Oxydationsgeschwindigkeit in lebenden Zellen, wenn wir den Lecithingehalt einer Zelle einerseits, ihren Sauerstoffverbrauch anderseits einer Vergleichsrechnung zugrunde legen? Die Antwort lautet, daß sich die Größen: Lecithinoxydationsgeschwindigkeit in vitro und Oxydationsgeschwindigkeit in der lebenden Zelle, bezogen auf ihren Lecithingehalt, recht nahe kommen; als Beispiel sei hier erwähnt, daß die Oxydationsgeschwindigkeit einer gegebenen Menge lebender Seeigel-Spermatozoen in dem aus ihr bereiteten Alkoholätherextrakt bei Zugabe von Eisensalz wiedererhalten werden kann. Freilich sind die Eisenkonzentra-

Hoppe-Seyler's Zeitschrift f. physiol. Chemie. LXXXV. 
4140 . Warburg und 0 . Meyerhof, Oxydation von Lecithin usw.

tionen in Zellen, wenn man ihren Eisengehalt auf ihr Gesamtvolumen bezieht, kleiner als die von uns in vitro angewandten; aber wir müssen bedenken, daß uns die Eisenkonzentrationen an den Reaktionsarten in der Zelle unbekannt sind.

Andere wichtige Zellbestandteile sind auch bei Gegenwart von Eisensalz gegenüber Sauerstoff beständig; im besonderen haben wir das nachgewiesen für Nucleinsäure (aus Thymus), Histon (aus Arbaciasperma), Eieralbumin, Traubenzucker und Ölsäure. 